\title{
ASR: Practical investigative techniques and field monitoring systems used to assess ASR for service life modeling.
}

\author{
Irene Matteini ${ }^{1, *}$, Paul Noyce $^{2}$, Gina Crevello ${ }^{3}$ \\ ${ }^{1}$ Echem Consultants, Technical Operation Manager, New York, USA \\ ${ }^{2}$ Echem Consultants, Technical Director, New York, USA \\ ${ }^{3}$ Echem Consultants, Principal, New York, USA
}

\begin{abstract}
Alkali Silica Reaction (ASR) is a common deterioration mechanism affecting many concrete structures of any type and age. Initially identified more than 60 years ago (Stanton, 1930), this mechanism is based on the chemical reactions between certain siliceous minerals present in the aggregate and the alkalinity of the concrete in the presence of moisture (internal RH). While certain deterioration patterns are clearly associated with ASR, such as gel exudation, aggregate expansion, and characteristic cracking, the material degradation can often be misdiagnosed to the untrained eye. In addition, certain elements of a structure can be severely affected while neighboring elements of the same batch/ mix design do not bear signs of deterioration or impact. Thus far, in situ field monitoring of ASR affected structures is related to moisture measurements, electrical resistivity, expansion, service life models are based on fracture mechanics of the aggregate. The impact to the concrete is loss of integrity, decreased compressive strength, shear and tensile strength. Some observed structures have split, with such force, that the concrete structure had cracks greater than $25 \mathrm{~mm}$ where steel retention bands have split. The authors of this paper were engaged in two instances to provide service life assessments for 'corrosion related degradation' on ASR affected structures. In all instances the elements which were assessed were structural, load bearing elements, which if failed could pose a significant risk to owner, user, or end recipient. The need to develop an assessment technique for monitoring and service life assessments which are practical and efficient is being developed. The paper will discuss the development of the approach, from visual indicators identifying condition hierarchies, to long term condition monitoring for various concrete parameters combined with laboratory testing (expansion and residual alkalis) and mathematical modeling. Three case studies will be presented to illustrate conditions and process.
\end{abstract}

\section{Introduction}

The expansion of concrete generated by the reaction between cement and aggregates is commonly referred to as Alkali Aggregate Reaction (AAR). The most common mechanism is referred to as Alkali Silica Reaction (ASR) which is defined as the reaction between the alkali ions present in concrete and reactive siliceous aggregates.

First studied by Thomas E. Stanton [1] of the California State Division of Highways in the 1930s, ASR is one of the most critical forms of deterioration that has occurred in concrete structures around the globe. In the United States, Parker Dam in Arizona was one of the first major structures to be diagnosed with ASR in the 1940's shortly after Stanton's study.[2] Built in 1934, this dam is still in use today after 86 years.

ASR is a chemical reaction that requires four main ingredients to be present for the reaction to occur: hydroxyl ions, alkali metal ions, reactive silica aggregates and sufficient moisture. In summary, the hydroxyl ions available in the pore structure will attack and provoke the destruction of the atomic bonds of the siliceous compounds causing the silica to dissolve.

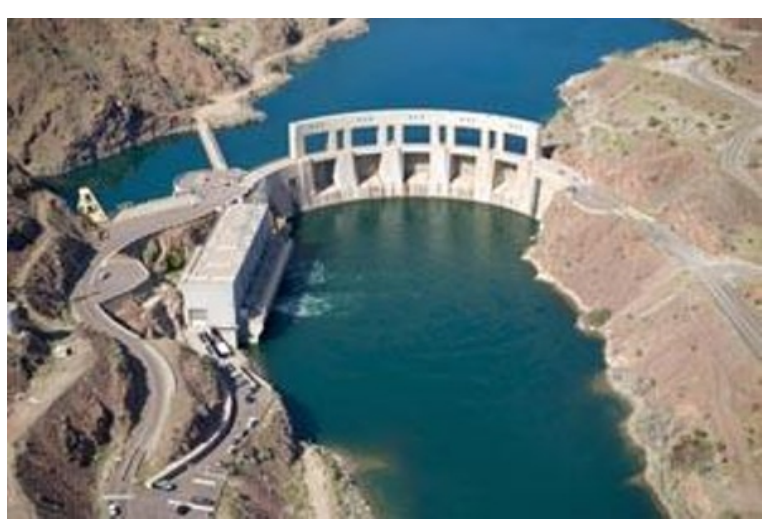

Fig. 1 Aerial view of Parker Dam. Courtesy of Bureau of Reclamation

Then, the alkali ions react with the $\mathrm{Si}(\mathrm{OH})_{4}$ complexes forming a $(\mathrm{Na}, \mathrm{K})-\mathrm{Si}-\mathrm{OH} \mathrm{Gel}$ around the edges of the aggregate. In the presence of a sufficient level of moisture, the gel expands generating stresses which are responsible for the formation of cracks. [3] The reaction is illustrated in Fig. 2. 


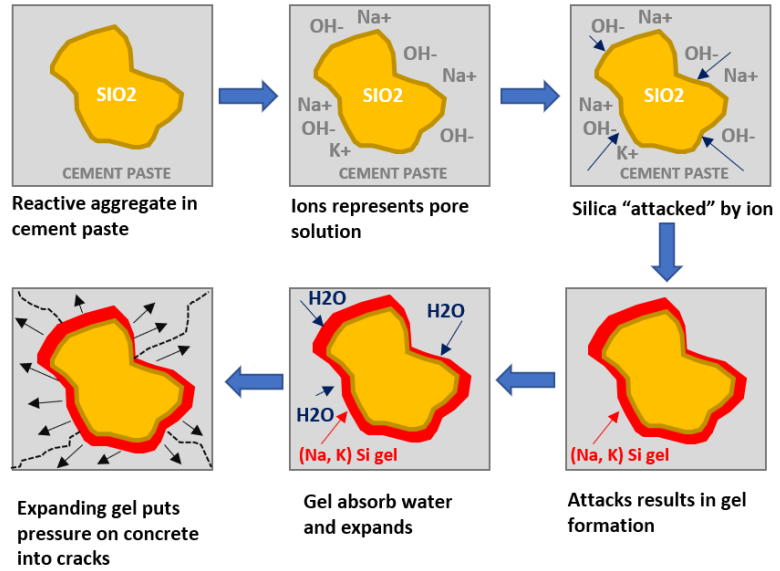

Fig. 2 Diagram illustrating the ASR Mechanism. Courtesy of Echem Consultants.

This swelling has the potential to induce tensile stresses within the concrete and can lead to the appearance of cracking with a pattern that depends on the geometry of the structure, and the layout of the reinforcement. [4] The typical cracking pattern is so called "map-cracking" which consists of a network of cracks randomly distributed from which a whitish gel will leach out of the concrete as illustrated in Fig. 3.

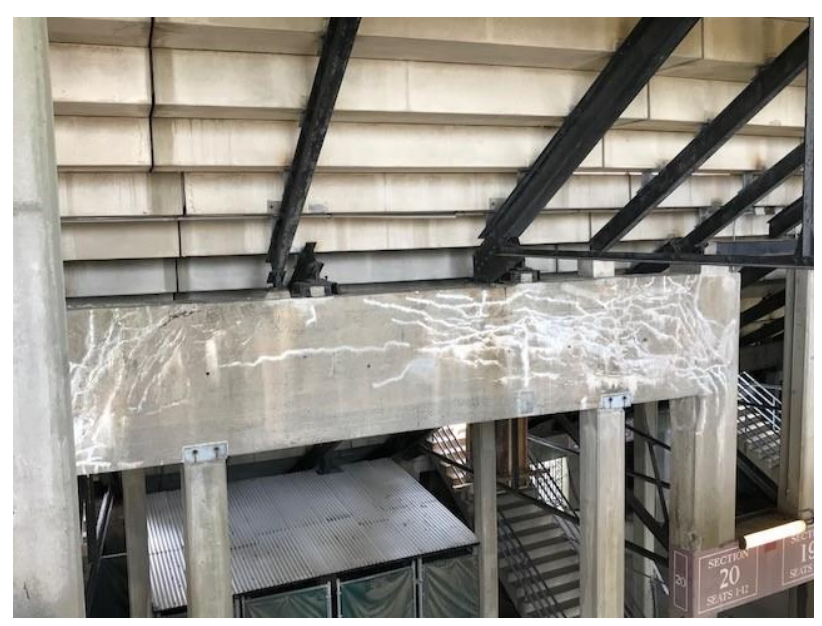

Fig. 3 Typical ASR Crack Mapping. Courtesy of Echem Consultants.

Besides the typical crack mapping of ASR, another typical ASR form of deterioration is referred to as "Popouts". This consists of a reactive aggregate undergoing expansion causing the concrete to detach leaving the reactive aggregate behind. [5] This is generally a localized phenomenon as shown in Fig. 4.

The main four ingredients available have an impact on the severity of the reaction that can occur in concrete structures. Each ingredient is briefly described below.

\subsection{Reactivity of Aggregate}

The quantity of reactive silica present in the aggregate mix determines the severity of the reaction. The reactivity of the silica minerals depends on their crystal structures.

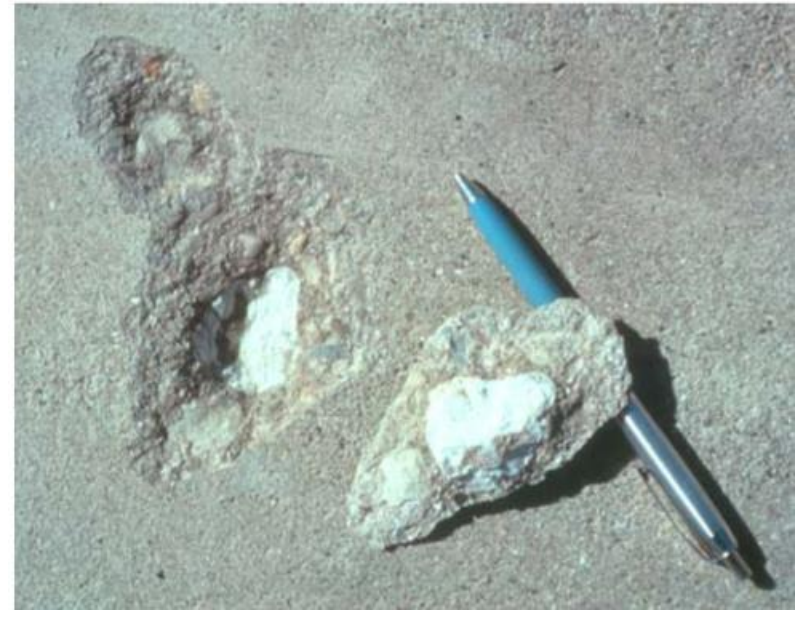

Fig. 4 "Pop-out" effect of ASR deterioration. [4]

For example, opal has a very disordered structure and is the most reactive form of silica. While, pure, undeformed quartz with an ordered structure is generally not reactive. [4]

\subsection{Alkali Content}

The alkali content present in the concrete plays an important role as well. Given the presence of reactive aggregate in the mix, using a low effective alkali content can prevent the reaction occurring. As shown in Fig. 5, if using a concrete with a $\mathrm{Na}_{2} \mathrm{O}$ content less than $3 \mathrm{~kg} / \mathrm{m}^{3}$ in the presence of chalcedony, a typical aggregate with intermediate reactivity, it will result in a negligible reaction. [6]

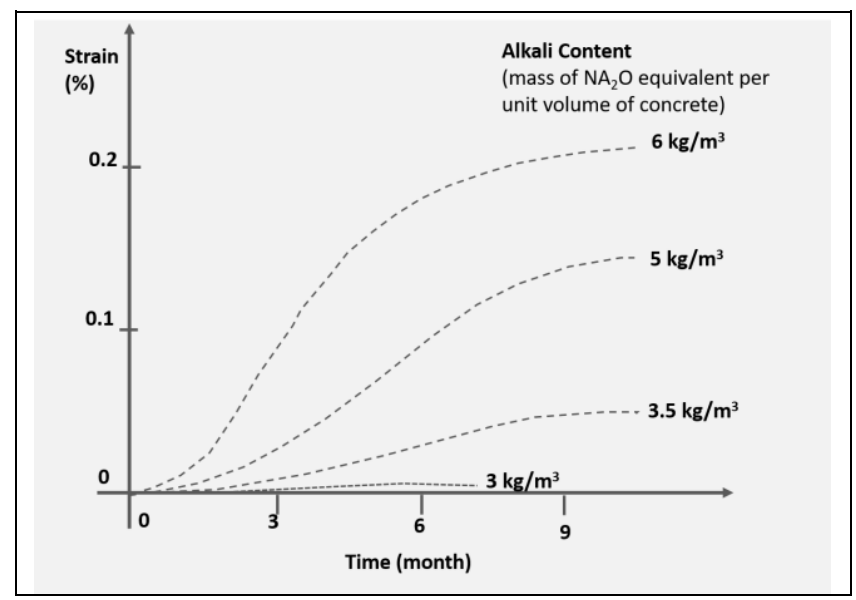

Fig. 5 Behaviour of concrete with reactive aggregate containing chalcedony as a function of Alkali content. [6]

External alkalis such as deicing salts or airborne salt in marine environments do not generally contribute significantly to the total alkali content and do not increase the risk of ASR given the slow rate of penetration into the concrete.[7]

\subsection{Type and Quantity of Cement}

Another ingredient that can be added as a form of prevention is the use of a pozzolan or blast furnace slag cement. Thus, this ingredient besides adding workability 
to the mix, it reduces the concentration of $\mathrm{OH}^{-}$ions in the pore solution of the cement paste as the hydroxyl ions are being consumed by the pozzolanic reaction. Furthermore, the alkali movement is reduced as a result of the lower permeability of the pozzolan and blast furnace in the cement paste.

\subsection{Environment}

As previously discussed, the environment plays an important role as ASR can only occur in the presence of moisture. It has been observed that in an environment with a relative humidity below $80 \%$, alkalis and reactive aggregate can coexist without causing damage. Temperature influences the reaction as well, warmer temperature facilitates the reaction to occur faster.

As engineering professionals, understanding the ingredients that influence the rate at which this reaction occurs is the first step to understand the durability and service life. ASR is responsible for a reduction in strength and stiffness of concrete components and in some instances of the entire structure.

\section{Case Studies}

In the following section, two (2) case studies with ASR related problems will be illustrated. Different field investigative techniques and monitoring programs used to study this mechanism will be discussed. The two structures presented are very different in size and use but both united by fundamentally the same problem.

\subsection{Case Study One: Power Line Distribution Pole}

The first case study is focused on power line distribution poles located on the northeast coast of the United States of America. Installed in the late 1970's, the poles are pre-cast and pre-stressed concrete structure used to provide bus and switch supports for electrical utility lines.

The poles, originally installed with a projected service life of 100 years, represent a critical support structure for the power plants. The structures, while still erected, have been suffering from several modes of concrete and material failure overtime as shown in Fig. 6.

In 1964, the poles were first built and utilized to rebuild and upgrade the power line from 34.5 to $115 \mathrm{kV}$. Each pole was a centrifugally-spun concrete cylinder of pre-determined length.

During these years, the use of pre-cast, pre-stressed poles was common for electrical and infrastructure with applications such as railway ties, and electrical distribution poles etc.

Between 1972 and 1974, M. Van Buren played an important role in the development of numerous patents in regard to the construction of pre-stressed reinforced concrete tapered poles "which would provide uniform compressive units throughout the length of the utility pole".

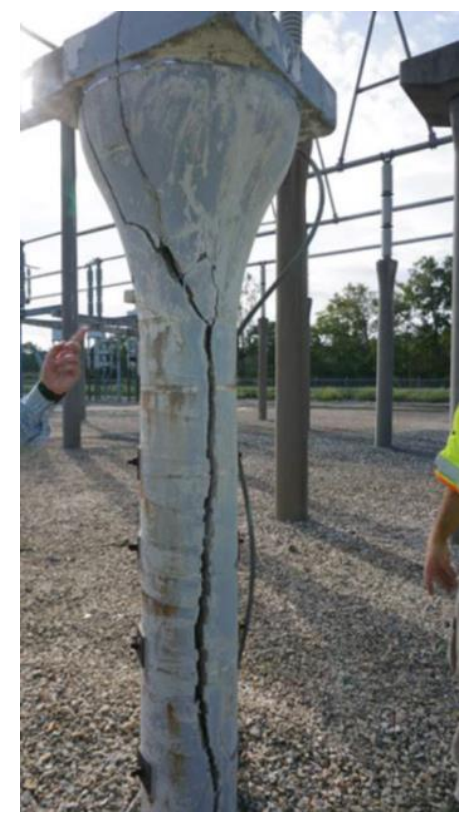

Fig. 6 Image of one pole used for this investigation. Courtesy of Echem Consultants.

According to Van Buren, the high weight to strength ratio of concrete is desirable to taper elongated vertical support members made of concrete. This permits a more efficient structure, since each cross sectional area may be tailored to the total weight being supported by it. As a result a uniform unit stress may be maintained throughout the structure.[8]

Today, this type of pole is still being used for lighting, sub-station bus-supports, and electrical transmissions distribution power lines.

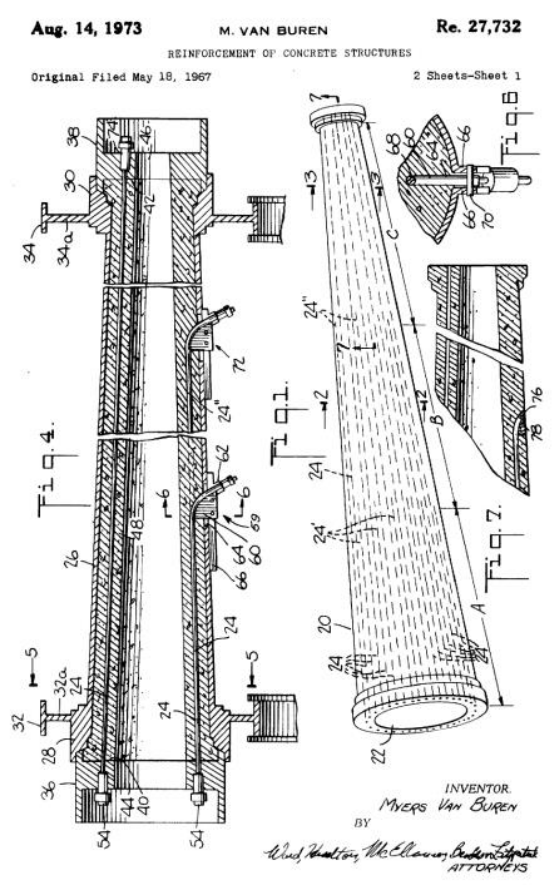

Fig. 7 Drawings extracted from M. V. Buren Patent, 1973 
The work scope for this investigation included ten (10) structures of different size and shape which were no longer in service due to the advanced level of deterioration.

A testing program was developed that included the following:

Table 1 Summary Testing Program

\begin{tabular}{|c|c|c|c|c|c|c|c|}
\hline \multirow[t]{2}{*}{ Reference } & \multicolumn{7}{|c|}{ Tests Carried Out } \\
\hline & $\begin{array}{c}\text { Corrosion } \\
\text { Rate }\end{array}$ & $\begin{array}{c}\text { Corrosion } \\
\text { Rate//Half-cell }\end{array}$ & $\begin{array}{l}\text { Electrical } \\
\text { Continuity }\end{array}$ & Resistivity & $\begin{array}{l}\text { Compressive } \\
\text { strength }\end{array}$ & $\begin{array}{l}\text { Ultrasonic } \\
\text { Pulse } \\
\text { Velocity }\end{array}$ & $\begin{array}{l}\text { Concrete } \\
\text { Cover }\end{array}$ \\
\hline IR-Pole 1 & $\otimes$ & $\otimes$ & 口 & $\otimes$ & $\otimes$ & $\otimes$ & $\otimes$ \\
\hline IR-Pole 2 & $\otimes$ & $\otimes$ & $\otimes$ & $\otimes$ & $\otimes$ & 口 & 口 \\
\hline IR.Pole 3 & $\otimes$ & 口 & 口 & $\otimes$ & $\otimes$ & 口 & $\otimes$ \\
\hline IR-Pole 4 & $\otimes$ & ㅁ & ㅁ & $\otimes$ & $\otimes$ & 口 & $\otimes$ \\
\hline IR:Pole 5 & $\otimes$ & ㅁ & 口 & $\otimes$ & $\otimes$ & $\otimes$ & $\otimes$ \\
\hline \begin{tabular}{|l|} 
IR.Pole 6 \\
\end{tabular} & $\otimes$ & ㅁ & 口 & $\otimes$ & $\otimes$ & 口 & $\otimes$ \\
\hline MF-Pole 1 & $\otimes$ & 口 & 口 & $\otimes$ & $\otimes$ & $\otimes$ & $\otimes$ \\
\hline MF-Pole 4 & $\otimes$ & 口 & ㅁ & $\otimes$ & $\otimes$ & $\otimes$ & $\otimes$ \\
\hline ME-Pole 5 & $\otimes$ & $\otimes$ & $\otimes$ & $\otimes$ & $\otimes$ & $\otimes$ & $\otimes$ \\
\hline MF-Pole 6 & $\otimes$ & $\square$ & 口 & $\Delta$ & $\otimes$ & $\otimes$ & $\otimes$ \\
\hline
\end{tabular}

The structures appeared in poor condition showing parallel hairline cracks and map cracking along their entire elevation. In addition, gel exudation was visible on the surface as shown in Fig. 8.

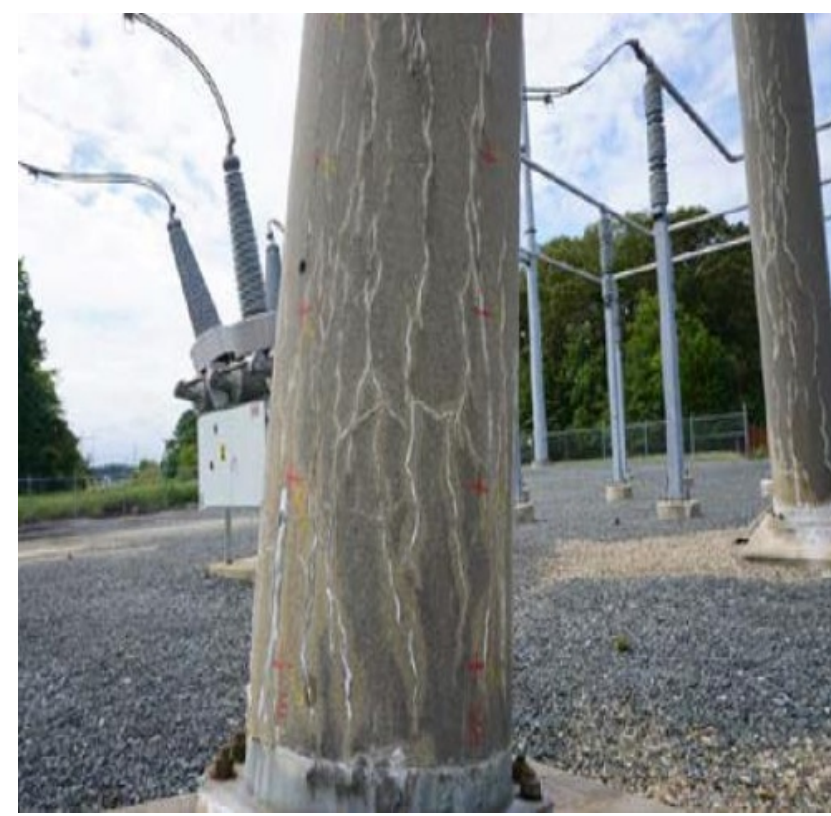

Fig. 8 Image showing ASR mapping cracking and whitish gel leaching at the bottom of one of the pole. Courtesy of Echem Consultants.

At the base of each pole, a grounding wire was attached which was electrically discontinuous with the reinforcement of the structure.

Little to no corrosion was found in nearly every pole, even when the steel tendons or reinforcing steel was exposed. Dust samples were collected to determine chloride levels which were found to be of negligible quantity and below the threshold for corrosion. In addition, no reduction in alkalinity was detected from the phenolphthalein test.

As a result of the petrographic analysis, it was determined that Alkali-Silica Reaction was the root cause of the concrete deterioration of these structures.
Multiple aggregate types utilized in the original mix design are known to be unstable in alkaline environments such as opal, and chert. Visible microcracking appeared in several of the aggregates showing gel exudation. In addition, a sufficient level of moisture was also detected due to a high water table on site.

Furthermore, given the pre-cast nature of the poles, Delayed Ettringite Formation (DEF) was also suspected as a potential deterioration mechanism that could have occurred in these structures over time. DEF is normally associated with steam cast cured members and when curing temperatures exceeds $158^{\circ} \mathrm{F}\left(70^{\circ} \mathrm{C}\right)$. DEF refers to the development of ettringite within the cement paste after the concrete has hardened. Like ASR, this mechanism will result in the formation of large cracks caused by the expansive reaction.

Beginning in the early 1980 s, DEF was reported to have caused destructive cracking of concrete sleepers (railway ties) in Europe and other pre-cast products in the United States. [9]

Numerous studies have stated that ASR and DEF could possibly relate to one another. In some of these cases, it has been concluded that ASR is the primary cause of cracking and deterioration, and that the subsequent precipitation of ettringite into the cracks is a secondary effect that may or may not cause further damage. [10]

Furthermore, the presence of microcracks in the aggregates appears to provide sites where secondary ettringite can grow and produce damage. Most petrographic examinations have shown that if one wishes to find ettringite in a deteriorated concrete, the first place one should look is within the transition zone. [11] In the end, DEF was ultimately not found in these structures.

Another unaswered question in regard to this case study is related to the location of the ground wire and its role in the ASR Reaction. As described before, each pole has a ground wire for lightning protection and ground fault dissipation. This ground wire is bonded to the substation grounding system and runs for the entire height of the structure which is discontinuous to the main steel reinforcement. The ground wire has the potential to generate an eletromagnetic field which could have played a role in the degree of this reaction given the size of the cracks that appear on the pole. In many of the poles, it was noted that the largest cracks, which developed for the entire height of these structures, occured close to a ground wire as shown in Fig. 9.

In conclusion, a monitoring program is being developed as part of Phase II of this study. On a final note, it should be noted that the level of deterioration of the poles has progressed to the point that the original design capacity has been altered. These structures should be considered structurally deficient and should be monitored until they are completely taken out of service. 


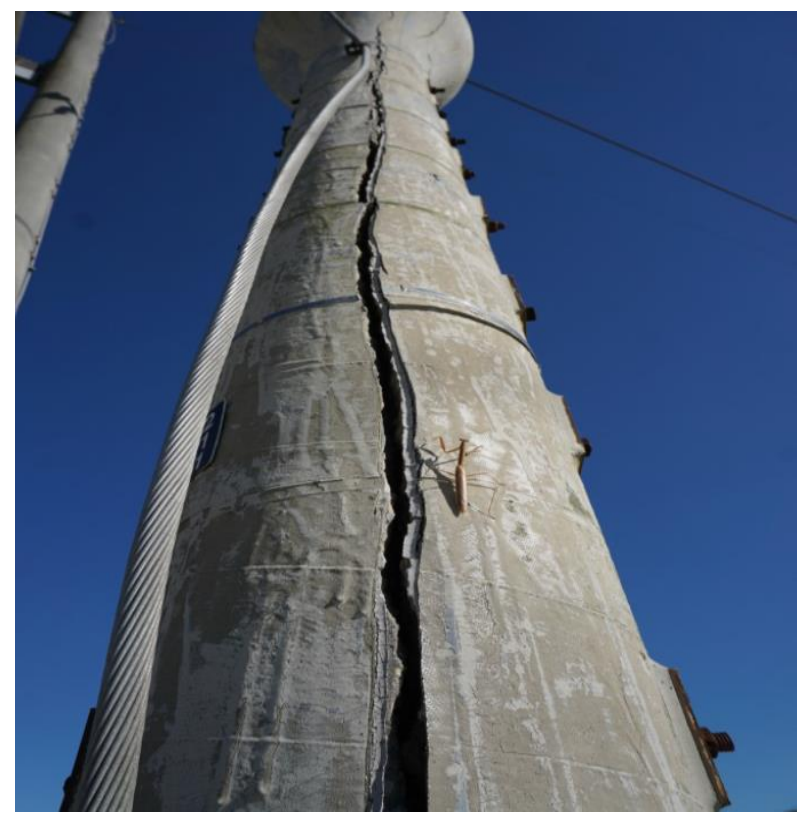

Fig. 9 Image showing a detail of one of the poles where the ground wire is located close to a large crack which extended for the entire height of the pole. Courtesy of Echem Consultants.

\subsection{Case Study Two: American Football Stadium}

A reinforced concrete football stadium located in a major city of the United States is our second case study. Built in 1903, the stadium was considered the first vertical concrete structure to employ reinforced structural concrete worldwide. Therefore, it was nominated as a National Historic Landmark in 1987.

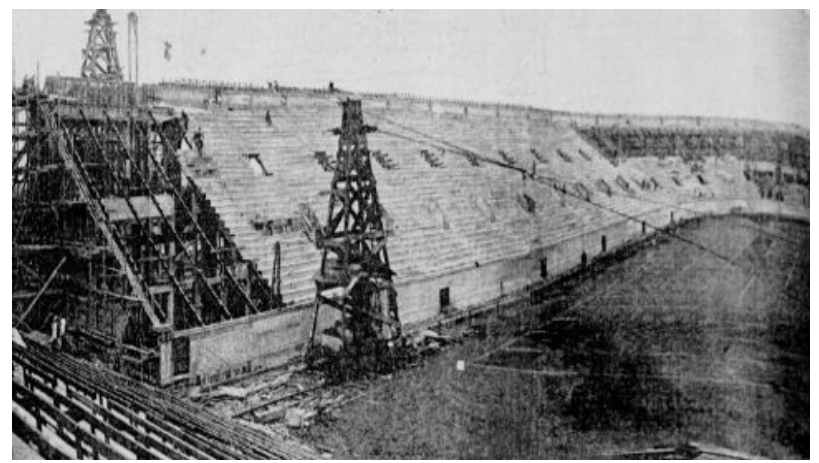

Fig. 10 Football Stadium under construction. Courtesy of Wikipedia.

Designed in a classical revival style inspired by the Panathenaic Stadium in Athens Greece, the stadium was erected in just $4 \frac{1}{2}$ months for a total cost of $\$ 310.000$.

This structure has been suffering from ASR for decades with numerous consultants and engineers working on it overtime. Multiple petrographic examinations have reported the presence of reactive aggregates in the cement paste, attributing the main cause of deterioration to ASR. Several components of the structure have been suffering from it including columns, beams, and the main exterior arches as shown in Fig. 11.

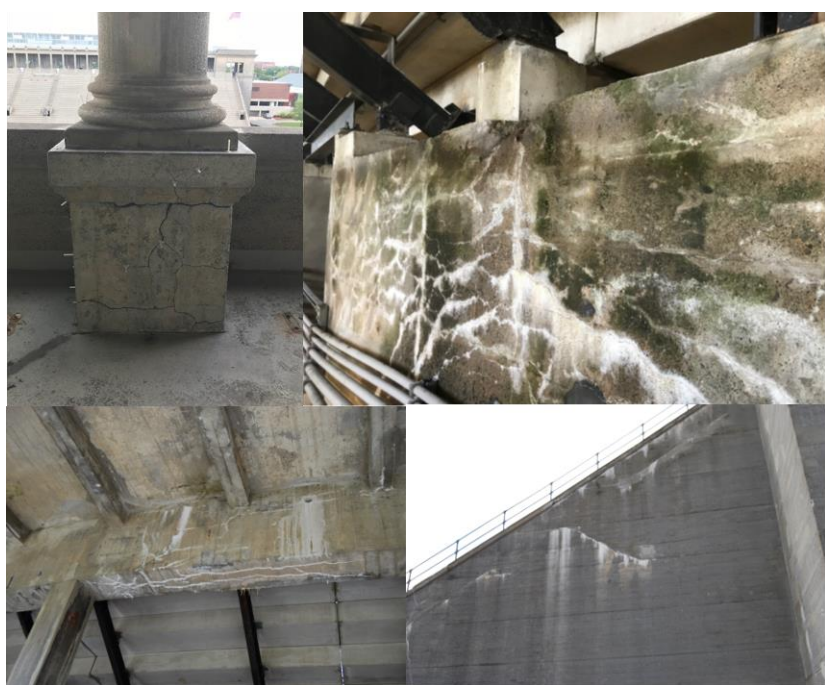

Fig. 11 ASR problem visible in structural component of the stadium. Echem Consultants.

Our scope of work was to develop a monitoring program to evaluate the existing structure. After an initial evaluation, the monitoring program included the use of the following techniques :

- Environmental Monitoring

- Ultrasonic Monitoring

- Digital Image Correlation (DIC)

Due to limited time and budget, one beam was selected for extensive monitoring. This beam representes a main component of the structure as shown on the drawing below.

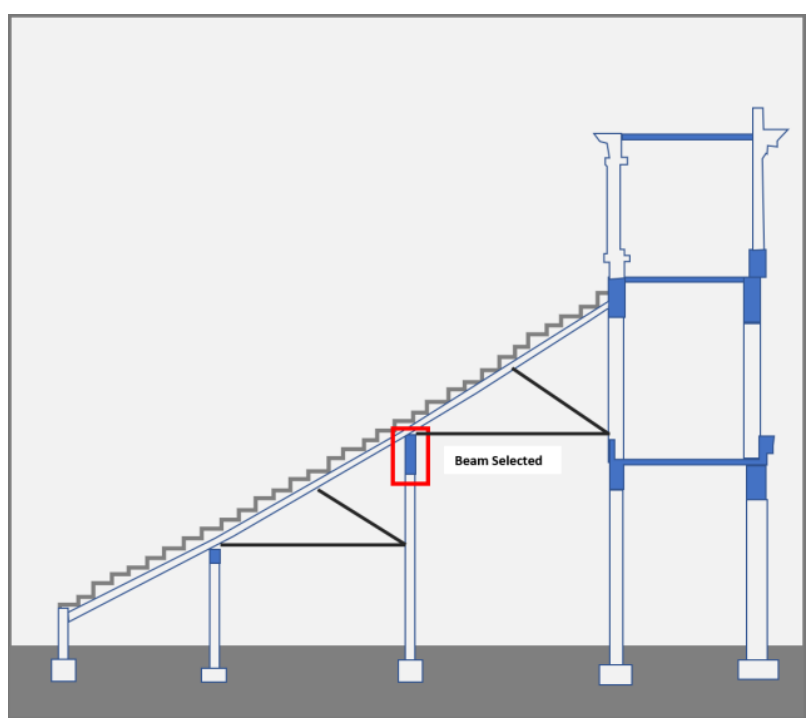

Fig. 12 Diagram representing the main cross section of the stadium. One beam was selected for this monitoring program. Courtesy of Echem Consultants. 


\subsubsection{Environmental Monitoring}

A temperature/humidity sensor was installed at the selected location recording data every hour. The sensor was embedded in the concrete and sealed in order to obtain accurate information on the internal temperature and humidity of the material.

At this time, the data collected so far shows high constant level of moisture within the concrete as shown in Fig. 13. In addition, the humidity level recorded was not influenced by the atmospheric condition as it remained reasonably constant inside the concrete. This also supports the visible sign of ASR on the surface.

The majority of the structure is exposed to the elements with limited water-proofing. As moisture plays a fundamental role within the ASR, this demonstrates a long-term issue.

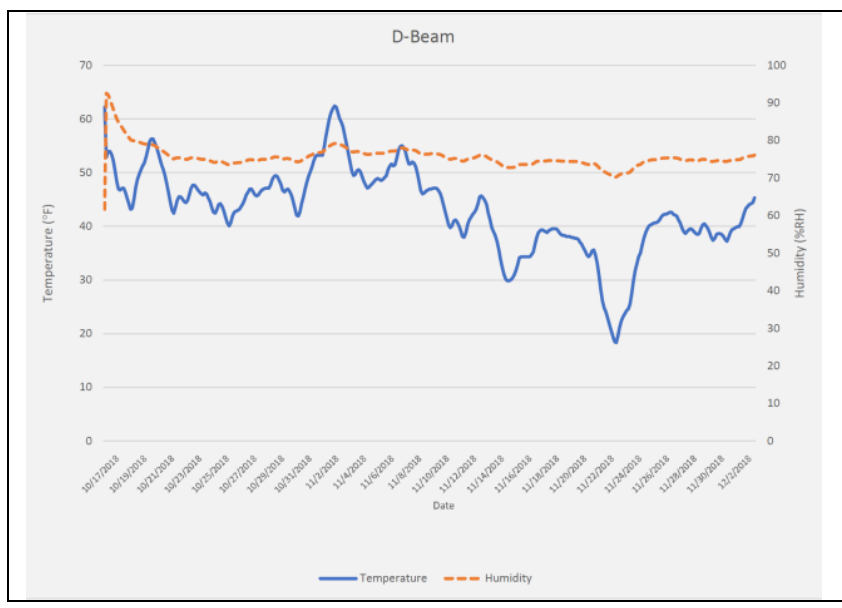

Fig. 13 Graph of Temperature/Humidity sensor at beam location. Courtesy of Echem Consultants.

\subsubsection{Ultrasonic Wave Sensors}

The main objective of this application, which is still in its development stage, is to monitor the progression of ASR.

This application is based on the use of the Coda Wave Comparison (CWC) technique [12]. Generally, ultrasonic signals can be divided into two portions: the coherent (early portion or p-wave) and the diffuse (late portion or coda wave). It is well known that the coherent portion of the wave is not sensitive to stresses until they reach a value that cause significant internal cracking. Hence, this approach is not suitable for service-life monitoring. In contrast, the coda wave field is influenced by any small changes in the material such as stress, temperature, and humidity variations, as well as aging/deterioration processes. The resulting internal changes are amplified by the multiple scattering properties observed in concrete affecting the stress wave field, which in turn alters the amplitudes and frequency content of the coda wave [12]. Fig. 14 illustrates the difference between conventional and coda wave ultrasonic monitoring, the main difference being that the latter is able to capture information from regions (highlighted in orange) that do not lie within the direct wave travel path. Over the last years, numerous researchers have started analyzing coda wave fields to monitor changes in concrete caused by cracking [14] and ASR [16]. A rigorous review of coda wave analysis techniques and their applications is provided in [15].
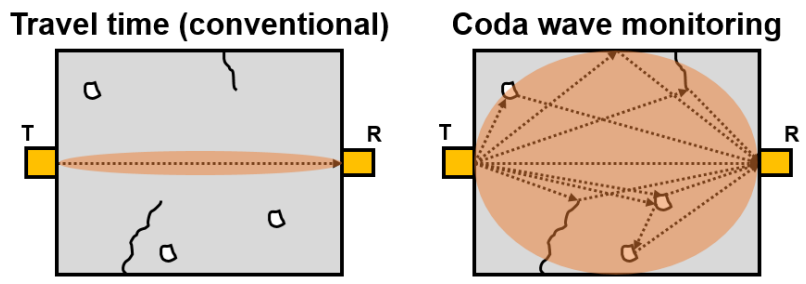

Fig. 14 Comparison of conventional (left) and coda wave (right) ultrasonic monitoring. Courtesy of Th. Schumacher.

A typical ultrasonic measurement setup is illustrated in Fig. 15: A constant and pre-defined pulse is transmitted into the material using an ultrasonic transducer and received by another one. This is done repeatedly at time intervals depending on the application. A high-speed data recorder captures and samples the ultrasonic waves arriving at the receiving transducer and stores them for later analysis.

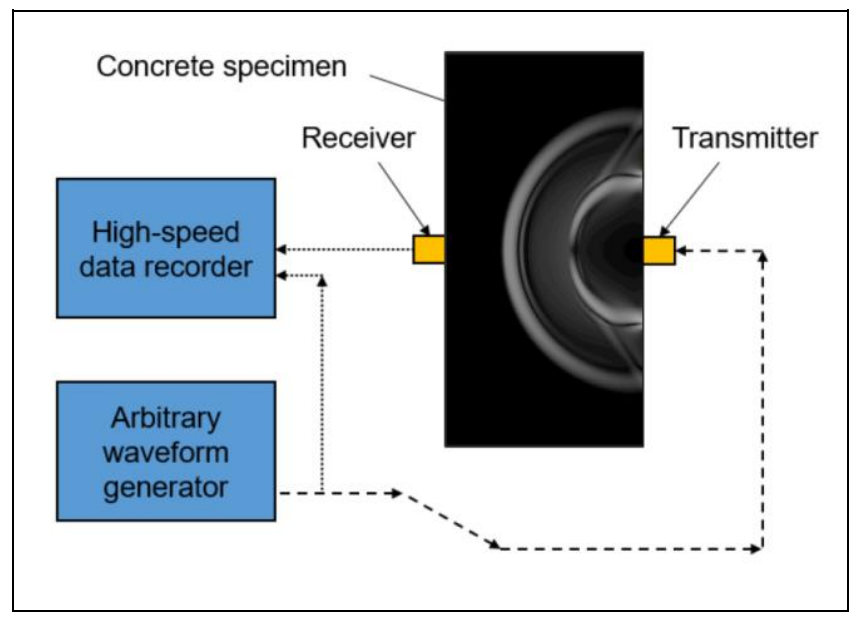

Fig. 15 Diagram illustrating the ultrasonic monitoring principle. Courtesy of Th. Schumacher.

In this application a commercial acoustic emission monitoring system (Vallen AMSY-5) is used to perform the measurements. The system both transmits and records ultrasonic signals at a sampling rate of $2 \mathrm{MHz}$. The transducers used were provided by Federal Institute for Materials Research and Testing (BAM) and are composed of a hollow piezoceramic cylinder of $20 \mathrm{~mm}$ diameter by $35 \mathrm{~mm}$ length. The electric connections are clamped to the piezoceramic part of the transducer. The total length of the transducer is $75 \mathrm{~mm}$ and $15 \mathrm{~mm}$ in diameter as shown in Fig. 16. [13]

A sample of a recorded ultrasonic signal is shown in Fig. 17. For each transducer, a $25 \mathrm{~mm}$ diameter hole was drilled to the middle of the beam and properly grouted, as shown in Fig. 18. Each transducer is connected to a pre-amplifier (Vallen AEP4) located close to the transducer. The transducers were embedded in one beam located 1.5 meter $(5 \mathrm{ft})$ apart, acting both as transmitter and receivers, as shown in Fig. 19. 


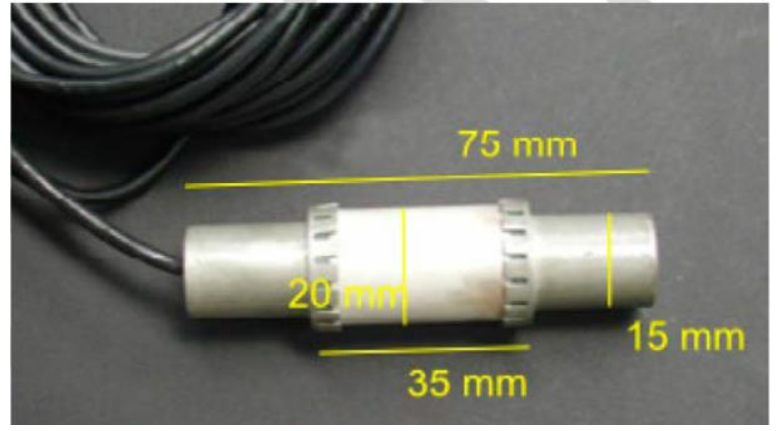

Fig. 16 Image of novel embeddable ultrasonic transducer. Source: [13].

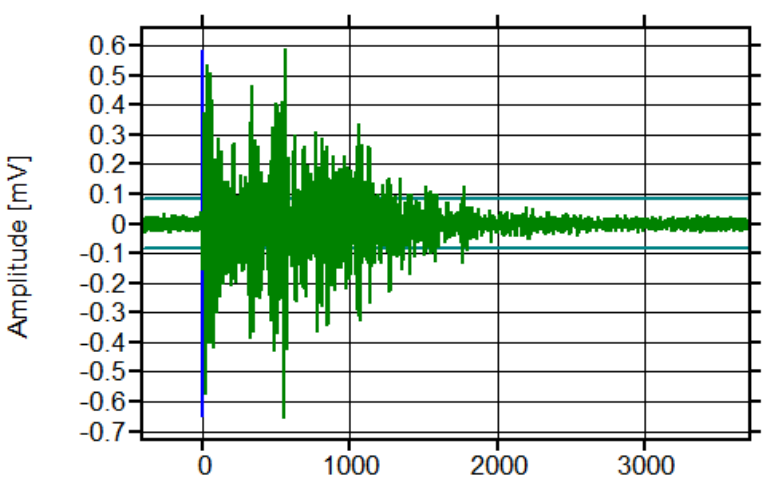

Fig. 17 Sample recorded ultrasonic waveform. Courtesy of Th. Schumacher.

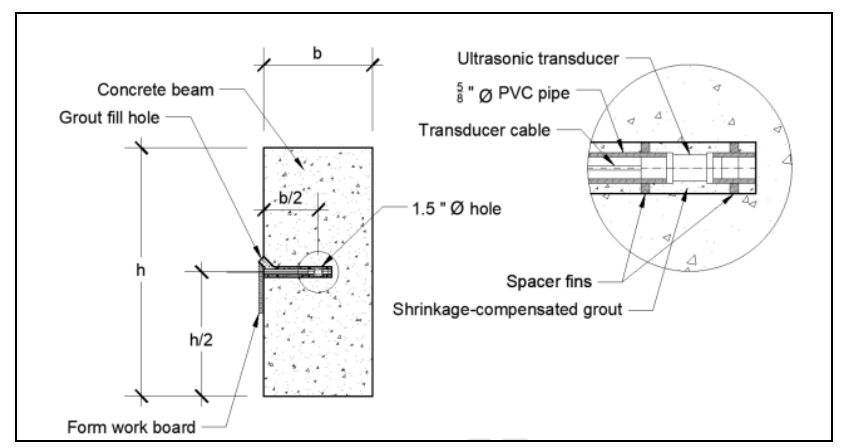

Fig. 18 Diagram showing the installation of the transducers at the selected beam. Courtesy of Th. Schumacher.

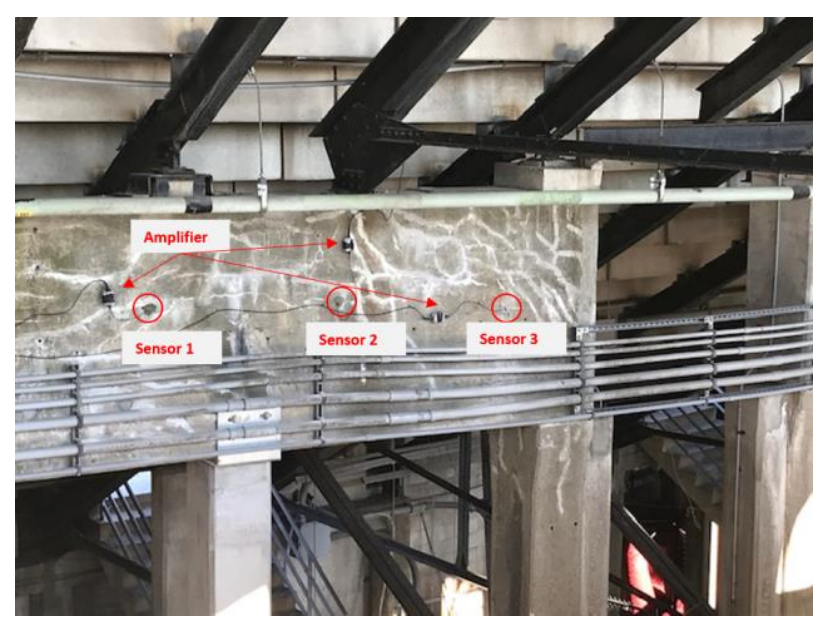

Fig. 19 Photo showing the installation locations of the three transducers at the beam. Courtesy of Echem Consultants.
While this project is still at an early stage, it is already showing promising results. One of the challenges is the fact that the stadium is actively used for sports and large events and is undergoing a large renovation project, which is adding noise to the system. Also, temperature and humidity changes affect the signals and this needs to be quantified.

On a final note, it is important to note that there are advantages of using this ultrasonic monitoring approach compared to the more traditional acoustic emission monitoring which has been employed at the stadium by others. With the proposed ultrasonic monitoring, which is an active technique, the source is controlled and repeatable and the recorded response can thus be directly associated with internal changes in the material. On the other hand, acoustic emission monitoring is a passive technique, recording active fracture processes in the material. Time, location, and nature of these sources are initially unknown, and occur spontaneously, i.e. they are not controlled by the operator and can thus not be repeated. Also, many of the other common sensors used, such as strain gauges and displacement sensors, are attached to the surface and thus represent a surface observation. In this application, the sensors are embedded and represent the internal condition of the material which is directly relevant for ASR.

\subsubsection{Digital Image Correlation (DIC)}

DIC (Digital Image Correlation) is an innovative nondestructive, non-contact optical technique used to measure strain and displacement. Originally developed by the National Physical Laboratory (NPL) in the UK, this technique works by comparing digital photographs at different stages of deformation. By tracking blocks of pixels, the system can measure surface displacement and build up full field $2 \mathrm{D}$ and $3 \mathrm{D}$ deformation vector fields and strain maps. [17] No special cameras or equipment is required which makes this technique very affordable.

At the stadium, a camera has been installed twentyfive feet $(7.6 \mathrm{~m})$ from the beam in order to obtain an image representing the component in its entirely as shown in Fig. 21. A Fujifilm X-T2 mirrorless camera has been used to collect one picture every four hours. After collection, the pictures are processed by using Matlab. The software overlaps pictures and elaborates the pixels to determine changes in the component.

In conclusion, the aim of this study is to correlate data collected by the environmental monitoring, ultrasonic sensors and the DIC pictures. Although at an early stage, the goal is to develop a network of monitoring sensors installed in different components of the structure which will be able to provide a holistic picture of the on-going condition of the entire structure for service life prediction. 


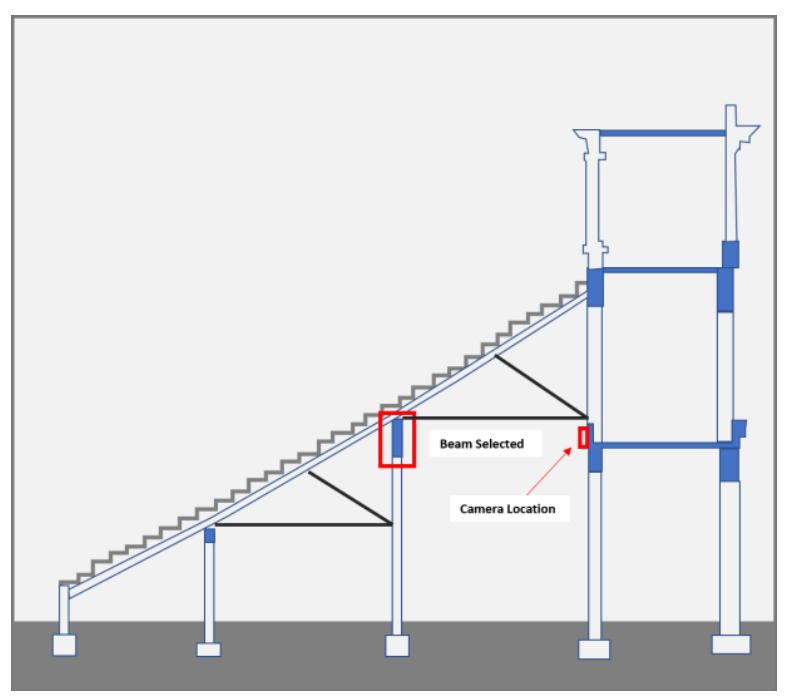

Fig. 20 Diagram showing the location of the camera in relation to the beam. Courtesy of Echem Consultants.

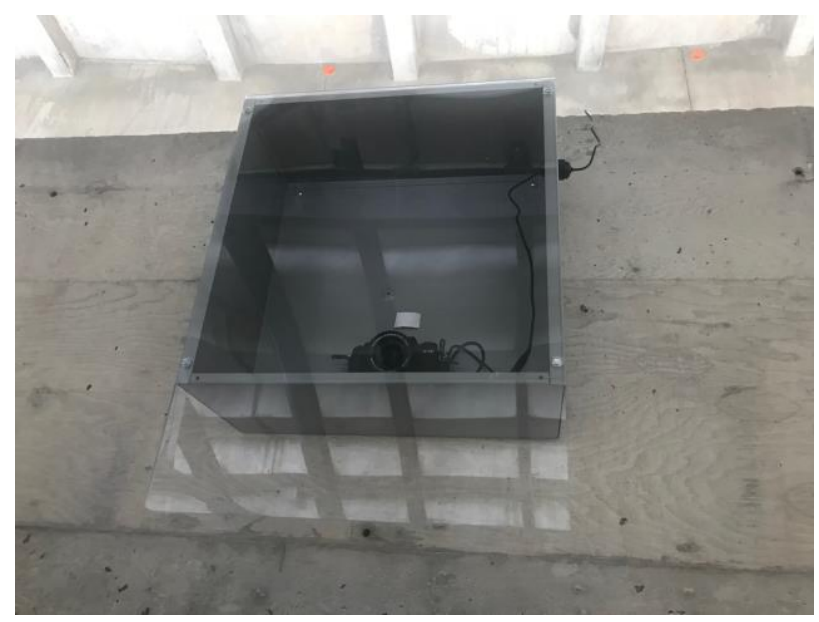

Fig. 21 Picture of the Camera Box installed at the stadium. Courtesy of Echem Consultants.

\section{Conclusions}

This paper attempts to illustrate the complexity of ASR and its potential impact in the service life of buildings and infrastructure. Using a diverse array of techniques, the aim of this study is to develop monitoring program in order to extend the service life of a component or of the entire building affected by ASR.

ASR is found in the cement paste coming from its reactive aggregate and the natural alkalinity of cement, therefore monitoring represents the best approach for any structure suffering from it.

Together with monitoring, several repair methods have been implemented overtime in order to help reduce the rate of deterioration. Unfortunately, in some cases, attempted repair methods have made the damage worse, for example by sealing the cracks. In addition, coating is another common method used to protect the concrete surface from excess moisture ingress. Different types of coatings have been used over time from silanes, acrylic rubber to epoxy etc. Unfortunately, in some instance, coatings have not been able to protect the concrete from moisture already present within the concrete and they do require to be reapplied over time. Gloablly, the use of lithium has shown some success, but the technique is less practicable for an entire structure.[18]

Thanks to new technology and advanced knowledge of this phenomenon, preventive measures have been implemented to prevent ASR in new construction in the United States and around the world by the use of nonreactive aggregates, limiting the alkali content of the concrete, use of supplementary cementing materials and ultimately the use of lithium-based admixtures.

\section{Acknowledgement}

A special thanks to Professor Thomas Schumacher of Portland State University and Ernst Niederleithinger of The Federal Institute for Materials Research and Training in Germany (BAM) for the on-going collaboration.

\section{References}

1. T.E. Stanton, "Expansion of concrete through reaction between cement and aggregate". Engineering News-Record, No. SP-249-1 (1940).

2. Meissner, H.S., Cracking in concrete due to expansive reaction between aggregate and highalkali cement as evidenced in Parker Dam. Proceedings, Am. Concrete Inst.,57, pp.549-568, (1941)

3. Lima, Mehdi, CFRP Strengthening of ASR Affected Concrete Piers of Railway Bridges. 9th International Conference on Bridge Maintenance, Safety and Management, (2018)

4. L. Bertolini, et al., Corrosion of Steel in Concrete, Wiley-VCH, pp.63-65 (2013)

5. FHWA-HIF-13-019, pp 43 (2013)

6. R.G. Sibbick, C.L. Page, Threshold alkali contents for expansion of concretes containing British aggregates, Cement and Concrete Research, 22, pp.990-994 (1992)

7. J.H.M Visser, R.B. Polder, Alkali Silica Reaction in concrete penetration of Alkalis, TNO Building and Construction Research Report 2000-BT-MK-R0207, (2000)

8. M. V. Buren, Reinforcement of Concrete Structures United States Patent, Original Filed 1967, Reissued 1973 (1973)

9. W. G. Hime, Delayed Ettringite Formation - A concern for pre-cast concrete, PCI Journal JulyAugust, (1996)

10. M.D.A. Thomas, Delayed Ettringite Formation in Concrete. Recent Developments and Future directions, Report University of Toronto, (1998).

11. FHWA/TX-06/0-4085-1, Alkali-Silica Reaction and Delayed Ettringite Formation in Concrete A Literature Review, (July 2001, Rev. February 2006)

12. A. Hafiz, T. Schumacher, Monitoring of Stresses in Concrete Using Ultrasonic Coda Wave Comparison 
Technique, Journal of Nondestructive Evaluation, 37, pp.73, (2018)

13. E. Niederleithinger, J. Wolf, F. Mielentz, H. Wiggenhauser, S. Pirskawetz, Ultrasonic Transducers for Active and Passive Concrete Monitoring, Sensors 2015, 15(5), 9756-9772 (2015)

14. J.B. Legland, Y. Zhang, O. Abraham, O. Durand, V. Tournat, Evaluation of crack status in a metersize concrete structure using the ultrasonic nonlinear coda wave interferometry, J. Acoust. Soc. Am. 142, pp. 2233-2241 (2017).

15. T. Planes, E. Larose, A review of Ultrasonic Coda Wave Interferometry in concrete, CEM Concrete Research (2013)

16. D.P. Schurr, J.Y. Kim, K.G. Sabra, L.J. Jacobs, Monitoring damage in concrete using diffuse ultrasonic coda wave interferometry, In: AIP Conference Proceedings. pp. 1283-1290 (2011)

17. N. Mc Cormick, J. Lord, Digital Image Correlation, Materials Today, 10 (2013)

18. I. Sims, A. Poole, Alkali-aggregate Reaction in Concrete A World Review, CRC Press, pp.246-248 (2017) 